\title{
DISCURSO DEL DR. VÍCTOR GUEVARA PEZO EN OCASIÓN DE LA PRESENTACIÓN DE SU LIBRO “EL DERECHO A LA INFORMACIÓN FRENTE AL DERECHO A LA INTIMIDAD"*
}

\section{DR. VÍCTOR GUEVARA PEZO'S SPEECH AT THE PRESENTATION OF HIS BOOK “THE RIGHT TO INFORMATION VS. RIGHT TO PRIVACY"}

Agradezco a la UNIFÉ, especialmente a su Vice Rectora Doctora Victoria García García y a su Decano de la Facultad de Derecho Dr. Mario Romero Antola por la deferencia que han tenido de decidir la publicación del libro que hoy presentamos.

Agradezco asimismo al Dr. Ronald Cárdenas, ex Decano de la Facultad, por su valiosa presencia, sus interesantes comentarios y sus generosas expresiones para conmigo

Es un ensayo sobre el tema "El derecho a la información frente al Derecho a la intimidad". Este ensayo participó en el II Concurso internacional de ensayos jurídicos convocado por la Asociación de ex alumnos de la Escuela de Leyes de la Universidad de Harvard, obteniendo el primer puesto.

Trata de la permanente tensión, del antagonismo perenne, que se da entre esos dos derechos, ambos fundamentales e importantes.

Comienza refiriéndose a lo trascendental que es y ha sido para el hombre el reconocimiento de derechos. Por la limitación de páginas que impusieron las bases del Concurso no fue posible lamentablemente dedicar más espacio a este asunto.

$\mathrm{Al}$ respecto, resulta pertinente recordar que hasta la revolución americana de 1776 y la francesa de 1789 no había una declaración que de modo universal reconociera la vigencia de derechos en beneficio de todos los hombres del mundo. En otros términos y aunque suene increíble, la mayoría de los hombres no tenía derechos. Antes, en 1215, a través de la Carta Magna,

La presentación del libro se llevó a cabo el 31 de mayo de 2018 en el Salón de Conferencia de la Biblioteca Central de la UNIFÉ. 
y en 1869, mediante el Bill of Rights, los Señores de Inglaterra - o sea, sólo ese estrato superior de la sociedad inglesa, siguiente al que ocupaban los reyes había logrado que se le reconociera algunos derechos.

En la actualidad, es la Declaración de los Derechos Humanos de 10 de diciembre de 1948, aprobada por la Asamblea General de las Naciones Unidas, la que rige la protección y vigencia en casi en todo el mundo de esos derechos, que tienen la particularidad de recaer sobre atributos esenciales físicos y espirituales de los seres humanos y cuya supresión vulnera y lesiona gravemente la dignidad humana.

Los derechos que en esa Declaración reciben el calificativo de humanos, en nuestra Constitución de fundamentales y en nuestro Código Civil de derechos de la persona, tienen, a diferencia de todos los demás derechos las características principales de ser inherentes, innatos, intransferibles, indisponibles, esenciales, extrapatrimoniales, absolutos y autónomos.

Dentro de la larga y cuidada lista de derechos de la Declaración de 1948 se encuentran los que constituyen materia de estudio del libro que presentamos y comentamos: el derecho a la intimidad y el derecho a la información.

Vamos a ocuparnos primero del Derecho a la intimidad y después del Derecho a la información. Luego trataremos de la tensión, de la contradicción, del enfrentamiento que hay entre ellos en la realidad.

En el libro consignamos hasta 13 definiciones del Derecho a la intimidad. Para nuestro diálogo de hoy queremos quedarnos con una que nos parece breve y bastante completa. Dice Nerson en su artículo "La protección de 1" intimité" publicado en Paris en el Journal des Tribunaux que "consiste en tener un sector personal reservado a fin de hacerlo inaccesible al público sin la voluntad del interesado". Buscando mayor precisión podríamos añadir diciendo que "el derecho a la intimidad impide que otras personas ingresen sin consentimiento en la vida de uno". Esta precisión nos lleva a indicar que a nuestro juicio las personas vivimos en tres diferentes esferas de vida: 1) la pública, a la que todos tienen acceso sin que podamos hacer nada para impedirlo; 2) la privada, a la que tienen ingreso inevitablemente nuestros familiares y otras personas a las que dejamos entrar; y, finalmente, 3) la íntima, a la que sólo ingresan aquellos a los que queremos abrirles la puerta.

Ahora, qué hechos, qué situaciones, son los que constituyen, contienen o conforman la esfera de vida íntima. Novoa Monreal hace una relación muy completa: 
1) Aspectos concernientes a la vida amorosa y sexual.

2) Ideas y creencias religiosas, filosóficas, mágicas, que el individuo desea sustraer del conocimiento ajeno.

3) Aspectos noconocidos por extraños dela vida familiar, especialmente los de índole embarazosa para el individuo o para el grupo.

4) Aspectos o anomalías físicos no ostensibles.

5) Comportamiento del sujeto no conocido por extraños y que de serlo originaría críticas o desmejoraría la apreciación de éstos sobre aquel.

6) Afecciones de salud cuyo conocimiento menoscabe el aprecio que para fines sociales o profesionales pudieran tener los demás sobre el sujeto.

7) La vida pasada del sujeto en cuanto pueda ser motivo de bochorno para éste.

8) Contenido de comunicaciones, orales o escritas, de tipo personal dirigidas únicamente para el conocimiento de personas determinadas.

9) Orígenes familiares que lastimen la posición social y, en igual caso, cuestiones concernientes a la filiación y a los actos de estado civil.

10) El cumplimiento de funciones fisiológicas y hechos o actos relativos al propio cuerpo que son tenidos por repugnantes o socialmente inaceptables.

11) Momentos penosos de extremo abatimiento.

12) En general, todo acto, hecho o actividad personal no conocido por otros, cuyo conocimiento por estos produzca turbación moral o psíquica al afectado (desnudez, embarazo prematrimonial).

A esta extensa y, pienso, exhaustiva nómina agrega Milagros Tello Febres lo siguiente:

1) Ingresos económicos. 
2) Rentas.

3) Nivel de vida.

4) Pasivo.

5) Cantidades declaradas al fisco y tributos pagados.

6) Informaciones dadas y recibidas bajo secreto profesional.

7) Ambiente físico en el que se desarrollan los actos de la vida íntima, privada (el hogar, el domicilio, el trabajo).

El hecho de ejercer plenamente el derecho a la intimidad y de tener consiguientemente un espacio, una esfera inexpugnable a la que ingresen sólo los que el titular de ese derecho quiera, le permite a éste:

1) Rechazar las intrusiones en su vida íntima, no consentidas ni autorizadas.

2) Controlar la información que tengan otros sobre él, pudiendo por tanto prohibirles que la difundan y entreguen sin su permiso, con la facultad adicional de conseguir las corrección de la misma cuando aparezca equivocada.

3) Mantenerse en soledad.

4) Ejercer plena autonomía en la toma de decisiones pudiendo, en tal virtud, rechazar y remover toda presión e influencia externa que obstaculice o distorsione tal ejercicio.

\section{Nacimiento del derecho a la intimidad}

El Derecho a la intimidad nació en la universidad más antigua de los Estados Unidos, la Universidad de Harvard, fundada en 1636. Propusieron su reconocimiento dos entonces destacados estudiantes, Samuel Warren y Louis Brandeis, en el ensayo titulado "Right of Privacy" (Derecho a la intimidad) publicado en diciembre de 1890 en la revista de la Escuela de leyes de esa universidad (Harvard Law Review). Más tarde se convirtieron en ilustres juristas. Warren llegó a ser un consultor de renombre aunque murió a edad más o menos temprana, 58 años. Brandeis vivió más, hasta 
los 85 años y fue nada menos que magistrado de la Corte Suprema de los Estados Unidos. Warren y Brandeis escribieron el ensayo indignados profesionalmente por el hecho de que todos los sábados la gente esperaba con viva curiosidad la aparición de una revistilla de corte amarillo dedicada a publicar impunemente chismes y habladurías que envolvían la vida íntima de la gente que conformaba la alta, cerrada y conservadora sociedad bostoniana. Por sus páginas desfilaban nombres y apellidos destacados, protagonizando romances y amoríos, infidelidades, encuentros y desencuentros ciertos o imaginados, en un ambiente insano de escándalo y agravio. Se trataba pues de una evidente y lesiva invasión de la intimidad de las personas, no protegida en ese entonces por derecho alguno. Nótese que desde aquel hecho inicial, fundador del Derecho a la intimidad, se produce un choque entre los que quieren cautelar y cuidar Warren y Brandeis (la intimidad) y el supuesto derecho a informar de aquella revistilla.

Al postular el nacimiento del derecho a la intimidad, Warren y Brandeis revisaron y comentaron más de 30 casos tramitados en cortes inglesas y americanas. Entre ellos el famoso caso incoado por el Príncipe Alberto de Sajonia-Coburgo-Gotha, esposo de la reina Victoria de Inglaterra, contra William Strange. Resulta que tanto el príncipe como la reina habían adoptado afición por la pintura, pero no querían que supieran esto sino sus más íntimos allegados. Strange tuvo ocasión de conocer algunos aguafuertes pintados por el príncipe y otros por la reina a través de un amigo de ellos de apellido Judge, a quien los artistas le habían obsequiado unas pinturas. Strange sacóindebidamente copia de ellas e hizo unos catálogos de las mismas, ofreciendo a quien los comprara obsequiarle unos ejemplares autografiados por sus autores. El príncipe montó en cólera e interpuso una acción judicial destinada a paralizar la circulación de tales catálogos. - Al comenzar el proceso parecían vencer los argumentos aparentemente razonables de Strange. Dijo éste que el hecho de que una persona sea propietario de algo no le da facultades para evitar o impedir que otros la vean y expresen sus comentarios u opiniones sobre ella; que en todo caso podía tratarse sólo de una violación de las normas que imponen buenas maneras, buenos modales, normas de trato social, mas de ninguna manera de una transgresión de carácter legal. La sentencia favoreció finalmente al príncipe. Se sustentó en la afirmación de que un propietario sí puede impedir que otros vean lo suyo. Pero además que en este caso particular se trataba de unos objetos que habían sido creados por la inspiración y los sentimientos de sus autores para conocimiento exclusivo de algunas personas y que no puede ser lícitamente posible ingresar al mundo de los deseos sentimientos, emociones y afectos personales sin el asentimiento de quienes lo expresan. 
Tanto impacto produjo el ensayo de Warren y Brandeis que en lo sucesivo comenzó a servir de sustento a numerosas sentencias de las cortes americanas que reconocieron y validaron la vigencia de ese nuevo derecho, el Derecho a la intimidad. Recordemos que en los Estados Unidos, como en los demás países regidos por el sistema del common law, los derechos pueden ser creados por vía jurisprudencial, a diferencia de lo que pasa en los del jus srcriptum, como el nuestro, en los que sólo pueden ser establecidos por ley.

Inicialmente, fue materia de confusión con otros derechos también importantes, como el derecho a la imagen, el derecho al honor o el derecho a la identidad, pero poco a poco se fueron decantando las semejanzas y diferencias para dar paso a la identificación clara, al reconocimiento cabal de los elementos que componen cada uno de esos derechos.

En nuestro ensayo revisamos y comentamos algo de la vastísima jurisprudencia que se ha producido en los Estados Unidos desde 1894. En esta ocasión nos referiremos sólo a algunas sentencias.

Por ejemplo, el caso resuelto en 1912 en el que Douglas enjuició y venció a Stokes por haber divulgado sin su consentimiento unas fotos que el primero había encargado tomarlas al segundo, de unos niños hijos suyos, siameses, fallecidos, unidos desde los hombros hasta la cadera.

El de Schulz, de 1914, contra la compañía de seguros Frankfurt. Schulz había sido ofrecido como testigo por alguien que demandó a la compañía de seguros. Ésta para inducirlo a que se mudara y no declarara en su contra contrató a unas personas que se encargaron de acosarlo, de seguirlo, día y noche. La sentencia le dio la razón a Schulz pues considero que lo hecho por la compañía de seguros afectaba la paz, la tranquilidad, la intimidad de Schulz.

El caso de Melvin contra Reid, de 1931. Gabrielle Darley había tenido una juventud licenciosa y disoluta, llegando incluso a ejercer la prostitución y ser incriminada en un crimen del cual salió absuelta. Años después, se casó con Bernard Melvin y se convirtió en una respetable dama. Reid, que era cineasta, se enteró de la agitada vida que había tenido la ya señora Melvin e hizo una película llamada "The real kimono" mostrando la vida pasada de la Sra. Melvin, mencionándola incluso por su apellido de soltera. La señora demandó para que se dejara de proyectar la cinta y se le pagara como indemnización la, para entonces, elevada suma de 50 mil dólares. El Tribunal de California, que hasta entonces había mostrado resistencia a reconocer el derecho a la intimidad, lo hizo en esta primera oportunidad, admitiendo que la demandante merecía el amparo de la justicia y concediéndole la razón. 
En el ensayo mencionamos varias normas dictadas en los Estados Unidos sobre el derecho a la intimidad.

Comentamos igualmente la contribución doctrinaria tan importante de William Prosser, que fuera Decano de la Facultad de Derecho de la Universidad de California y que escribió aquel notable artículo "Privacy", cuyos conceptos desarrolló después en el "Law of Torts". Destacamos asimismo la obra de quien es considerado exponente más calificado mundialmente en el estudio del Derecho a la Intimidad, el profesor Alan F. Westin, de la Universidad de Columbia, que publicó “Privacy and freedom”, libro de 487 páginas que va por la octava edición.

En Inglaterra, como lo decimos en el ensayo, no ha tenido el Derecho a la Intimidad desarrollo semejante al de los Estados Unidos. Ello se debe tal vez al carácter flemático de los ingleses, a su extremado cuidado por evitar que lo privado e íntimo se mezclen con lo público o a su inveterada renuencia a dictar muchas regulaciones. Lo cierto que ninguna existe para normar o regular el derecho a la intimidad, para protegerlo. La jurisprudencia inglesa tampoco se ha mostrado muy pródiga.

En Francia, en cambio, la jurisprudencia ha sido fértil respecto de este derecho; aún antes del ensayo de Warren y Brandeis que le puso bases doctrinarias tan consistentes. Todavía en 1858 se dictó una célebre sentencia. Se trataba de Elisa Félix, cuyo nombre artístico era Rachel, una artista de teatro aclamada en Francia y en toda Europa. Como mucha gente en aquellos tiempos, murió joven, a los 38 años y de tuberculosis. A su muerte, su hermana Sara Félix contrató a los conocidos fotógrafos Crette y Ghemar para que le tomaran unas fotos en su lecho de muerte; el contrato contenía el compromiso de que no obtuvieran más copias de las concertadas. Los fotógrafos violaron el compromiso facilitando unas reproducciones a la destacada pintora O’Donell que hizo a partir de ellas un retrato a lápiz que lo publicó el semanario L'Ilustracion. Sara demandó a la revista pidiendo una reparación y obtuvo una sentencia notable que le dio la razón, apoyándose en argumentos tan macizos como estos: "Por grande que sea un artista, por histórico que sea su nombre, tiene una vida privada distinta a la pública. Puede querer morir en la oscuridad después de haber vivido o precisamente por haber vivido en el triunfo...El hombre célebre tiene el derecho de morir oculto y si la familia después del último suspiro quiere hacer reproducir sus rasgos para ella sola, no se puede en nombre de la celebridad sobrevivir a la muerte, tocar esas cosas".

En 1850 el Tribunal de Casación de París dictó sentencia prohibiendo la publicación de unas cartas privadas enviadas por Benjamin Constant a Madame Recamier. 
En 1934, Jim Lemoine, conocido bibliotecario de París, venció en juicio a los herederos de Anatole France, propietarios de una editorial que había publicado "La rebelión de los ángeles", una novela en la que de modo reconocible aparece Lemoine internado en un manicomio, hecho que era cierto.

En 1965, el destacado actor Gerard Philipe consiguió que el Tribunal de Paris dispusiera el secuestro de toda la edición del "France Dimanche", en la que con fotos aparecía un relato de la penosa enfermedad que afectaba a su hijo.

En 1965, Pablo Picasso consiguió que el Tribunal de París mandara incautar todos los ejemplares del libro "Vivir con Picasso", escrito por Francois Gilot, narrando pormenores de la vida íntima que habían compartido más de 10 años.

Sobre Francia, he mencionado solamente casos de personas notorias entre todos los que aparecen en el ensayo.

Después de haberse producido copiosa jurisprudencia y doctrina sobre el derecho a la intimidad, el legislador francés incorporó en su viejo Código de 1804 un nuevo artículo 9 destinado a defender este derecho.

Aunque por mucho tiempo no ha andado España al compás de los cambios e innovaciones en materia jurídica, sobre todo en cuanto a derechos fundamentales, no es posible dejar de mencionarla aunque sea para destacar su atraso debido sin duda a la fuerte marca autoritaria impresa sobre su historia. Y es ineludible mencionar a España porque de un modo $u$ otro existen entre nuestros países nexos indelebles, a veces invisibles, que nos unen en todos los órdenes. No es posible pues borrar 288 años de vida colonial con 197 de República imperfecta, ni existe - por último- razón para hacerlo. Lo destacable ahora de España es que con motivo de su retorno a la democracia ha hecho suyos, por su Constitución de 1978, los derechos humanos y expresado en el artículo 18 de la misma que garantiza -entre otros- el derecho a la intimidad. Posteriormente, ha promulgado la Ley de 5 de mayo de 1982 destinada especialmente a proteger los derechos al honor, a la intimidad y a la propia imagen.

La Argentina es, desde hace tiempo, fuente de consulta y sede de la mejor doctrina jurídica. Cada año sus numerosas editoriales jurídicas ponen en manos de los lectores -nosotros entre ellos- cientos de nuevos libros sobre las diversas materias del Derecho. En el campo civil es particularmente fecunda esa labor que proyecta su luz sobre todos los países americanos de 
habla hispana. Es por eso que, nuestra atención mira siempre con expectativa lo que allá se diga o dirá, se haga o se hará. El 15 de octubre de 1975 se dio la ley argentina $N^{\circ} 21113$ que añadió al Código Civil de ese país el artículo 1971 bis que protege el derecho a la intimidad en los siguientes términos:

El que arbitrariamente se entrometiera en la vida ajena publicando retratos, difundiendo correspondencia, mortificando a otros en sus costumbres o sentimientos o perturbando de cualquier modo su intimidad, y el hecho no fuese delito penal, será obligado a cesar en tales atrocidades si antes no hubiese cesado, y a pagar una indemnización que fijará equitativamente el juez de acuerdo con las circunstancias; además, podrá éste, a pedido del agraviado, ordenar la publicación de la sentencia en un diario o periódico del lugar, si esta fuere procedente para una adecuada reparación. (Artículo 1975 bis, Código Civil argentino)

En el Perú, la primera publicación que puso a consideración de la comunidad jurídica la necesidad de reconocer y proteger el derecho a la intimidad fue la que hizo el profesor Carlos Fernández Sessarego, bajo el título de "Consideraciones sistemáticas preliminares para la revisión del Libro I del Código Civil" en los números 445 y 446 de la revista "El Mercurio Peruano", meses de mayo y junio de 1964.

Posteriormente, la Constitución de 1979 estableció en su artículo 2, inciso 5, por vez primera en la historia del país, que la persona tendría el derecho a la intimidad.

Más adelante, el Código de 1984, hoy vigente, incluyó en sus artículos 11, 14 y 16 tres normas destinadas a cautelar este derecho. No contienen, sin embargo, estos artículos disposiciones suficientemente protectoras. El artículo 14, que es el central, principal para el efecto, se limita a prohibir a quien hubiera tomado conocimiento de hechos pertenecientes a la intimidad de una persona, que los ponga de manifiesto, mejor dicho que los haga públicos, que los divulgue sin el asentimiento de esa persona. No contiene disposiciones esenciales como la de prohibir la intrusión en el mundo íntimo de las personas, la de consagrar la autonomía en la toma de decisiones, la de poder controlar la información que tengan de uno y actualizarla y rectificarla cuando fuese preciso; no ampara tampoco la soledad, paz y tranquilidad a las que tenemos derecho, de modo inviolable, todas las personas.

En el ensayo hacemos mención a algunas disposiciones dadas no hace mucho en el Perú relacionadas con el derecho a la intimidad, como 
las leyes 27489 y 27863 , sobre el funcionamiento de las centrales privadas de información así como la Ley de Bancos. Reclamábamos la dación de una ley de protección de datos personales, reclamo que ha sido satisfecho con la expedición de la Ley 29733.

A partir del año 1994, tanto en el Poder Judicial como en el Tribunal Constitucional, se han resuelto numerosos casos en los que se discutieron situaciones concernientes al Derecho a la Intimidad. Hemos hecho acopio y comentario breve de ellos.

Es muy importante mencionar, en tono si se quiere de denuncia o tal vez mejor de advertencia, los diversos medios o formas que se emplean para vulnerar la intimidad. En 1967, la Conferencia de Juristas Nórdicos hizo un recuento de ellos, que vale la pena recordar y está vigente:

1) El registro, mejor dicho la obtención de datos personales, de modo de poder perpetrar sin autorización la construcción de perfiles psicológicos que faciliten el manejo de esas personas.

2) La violación y registro ilegal de domicilios.

3) Los exámenes médicos, psicológicos y físicos, compulsivos.

4) Las declaraciones molestas, falsas o irrelevantes referentes a una persona.

5) La interceptación de la correspondencia.

6) La captación de mensajes telefónicos o de otra clase.

7) La utilización de aparatos electrónicos de vigilancia o escucha.

8) La grabación sonora y las tomas inconsultas de fotografías o películas.

9) Las intromisiones de la prensa.

10) La divulgación pública de hechos de la vida íntima.

11) La vigilancia, seguimiento o reglaje de una persona.

12) La realización de llamadas telefónicas repetidas e insistentes. 


\section{El Derecho a la información}

Hasta aquí hemos dicho todo lo principal que contiene el ensayo acerca del derecho a la intimidad.

Tratemos ahora del otro derecho, del derecho que se le contrapone, que se enfrenta en tensión y contradicción al derecho a la intimidad, que pretende someterlo en nombre de un interés superior; del Derecho a la información.

Definámoslo con Reniz: "Es aquel derecho fundamental que tiene toda persona a ser informada y a informarse de la verdad para juzgar por sí misma la realidad, con conocimiento suficiente". Esta definición, empero, expresa el contenido de este derecho únicamente desde el lado del informado. Preciso es considerarlo también desde la perspectiva del informador, del derecho y deber que éste tiene de hacer saber al público, con veracidad, todo lo que acontece en la sociedad, de hacer participar a las personas en la vida de todos los días, vida con miserias e infortunios, vida igualmente con alegrías, éxitos y grandezas.

El derecho a la información tiene, como que también es fundamental, los mismos caracteres que distinguen a los de su género.

El derecho a la información debe reposar en la vigencia plena del derecho a la libertad, en sus diversas manifestaciones; libertad de expresión, de opinión, de conciencia, de pensamiento y de creencia. La información dada sin ese imprescindible sustento es espuria, bastarda y apócrifa; responde a designios autocráticos y autoritarios; es ilegítima y contraria a los principios que deben guiar una vida social civilizada y democrática.

La Declaración de los Derechos Humanos de diciembre de 1948 atribuye tres poderes al Derecho a la información:

1) El de recibir información, que tienen todos los ciudadanos. Tal información ha de ser veraz, sobre hechos de interés e importancia públicos, dentro del contexto completo de la realidad, asequible por todos y rápida.

2) El poder de divulgar la información, que es el que tienen los medios y que debe cumplir los mismos requisitos que el poder anterior.

3) El poder de investigar, o sea el que tienen los medios de indagar, de escudriñar el fondo, los detalles y la verdad de los hechos 
divulgados. En el uso de esta facultad o poder, como en el de los otros, los medios deben actuar con serena ponderación, actitud responsable y diligente prudencia, sin incitar pasiones irracionales ni inclinaciones al escándalo a las que son muchas veces proclives las multitudes tumultuarias y algunos informadores.

La doctrina añade a esos tres poderes otros también importantes:

- El de guardar secreto sobre las fuentes de donde proviene la información.

- El de considerarse despedido arbitrariamente, que tiene el trabajador periodista que sea víctima de una imposición que pretenda obligarle a decir algo que vaya en contra de sus principios morales o cívicos.

- El derecho de todas las personas de conseguir que el medio que hubiera incurrido en inexactitudes o agravios publique la correspondiente rectificación.

Cuando sólo había prensa escrita como medio de información, el alcance y repercusión de este Derecho en la vida de las personas eran muy limitados. Ahora con la infinidad de avances de la ciencia y la tecnología, con la existencia de múltiples clases de medios (radio, televisión, internet), la información y el derecho que le corresponde llegan, para bien o para mal (más creo que para bien) hasta los lugares más distantes y remotos. Nuestra vida, la vida de todos los días, está sin duda atada, influida y, hasta me atrevería a decir, determinada por el inmenso torrente de información que se produce incesantemente.

\section{El derecho a la información frente al derecho a la intimidad}

Puestos frente a frente el Derecho a la información y el Derecho a la intimidad, ¿cuál de ellos debe primar?

¿Debe acaso vencer el deseo y la exigencia de los medios de hacer saber a sus lectores, radio oyentes y televidentes, todo lo que sucede con las personas sin importar si ello demanda invadir como fuera el mundo íntimo y cerrado de ellas? O ¿debe preponderar la valla, el obstáculo, el impedimento que oponga la persona para que su mundo íntimo sea siempre infranqueable, aun frente a la sociedad que requiere conocer hechos sucedidos en ese mundo para atender o resolver cuestiones que implican intereses superiores de justicia o seguridad? 
Es difícil, diría yo imposible resolver esa disyuntiva a través de una norma que establezca reglas o fórmulas rígidas. Pienso que la solución deberá darse siempre en cada caso ingresando a la esfera de la intimidad sólo cuando éste sea ese el único camino para atender intereses superiores.

En los años 60 del siglo anterior se produjo en Inglaterra un caso representativo de cuando, justificadamente, puede incursionar la prensa en la intimidad de una persona. John Profumo, de 48 años, casado, Ministro de Guerra del gobierno conservador de Mc Millan y miembro del Parlamento, conoció en una reunión a la modelo y bailarina de cabaret Christian Keller, de 19 años. Hizo fácil y rápida amistad con ella; establecieron relaciones íntimas. Sin embargo, resultó que Keller mantenía en el mismo tiempo relaciones íntimas con Yevgeni Ivanov, quien fue Agregado Naval de la Unión Soviética en Londres y espía de este país. Este hecho hizo suponer que le hubieran sido arrancados a Profumo secretos militares o que pudieran extraérselos en cualquier momento. Llamado Profumo al alarmado Parlamento negó haber sostenido relaciones íntimas con Keller. La prensa sin embargo no le creyó y, luego de hacer investigaciones, consiguió y publicó pruebas que acreditaban la clase de relaciones de ProfumoKeller. Esto obligó a Profumo a renunciar a sus cargos y a alejarse para siempre de la política. Motivó, asimismo, que corto tiempo después cayera por esa misma razón el gobierno con la dimisión de Mc Millan.

La prensa hizo bien en ingresar a la intimidad de Profumo y develar, por razones de seguridad nacional, lo sucedido.

Pero no siempre son así, justificadas, las intrusiones de la prensa. Muchas veces se producen para satisfacer la curiosidad morbosa de los lectores, oyentes y videntes y para, sobre todo, incrementar con ello el tiraje de los periódicos y la audiencia de los medios radiales y televisivos, con el consiguiente beneficio económico.

Así, por ejemplo, entre abril y octubre del 2011 el país siguió en congelado suspenso la trágica noticia de la desaparición de un joven estudiante de Agronomía, Ciro Castillo, quien con su enamorada, Rosario Ponce, había marchado de excursión al Colca. Luego de una desavenencia tomaron caminos distintos y a Castillo se le perdió el rastro. Entonces, su padre protagonizó una espectacular búsqueda de la que, día a día, daban cuenta los medios, en sus principales titulares. No importó que para atraer y afirmar la atención se usara innecesarias referencias a la vida íntima de la pareja ni que se tuviera que conocer interioridades de la familia del desaparecido. Después de ocho meses apareció el cadáver y terminó la sórdida novela. 
Otro caso es el de la muerte de la cantante Edita Guerrero, vocalista principal del popular conjunto Corazón Serrano que atraía la simpatía y adhesión de multitudes. Los médicos que asistieron al deceso certificaron que este se había producido como consecuencia de un aneurisma cerebral. De pronto alguien, anónimamente, denunció que la causa de la muerte no había sido un aneurisma sino el maltrato físico que le había inferido su esposo Paul Olórtiga. El Ministerio Público recogió esta denuncia y la hizo suya apoyándola en una necropsia realizada en condiciones irregulares. Cuatro años duró el proceso y el público, frente al regodeo de los medios, tuvo también que enterarse innecesariamente de circunstancias de la vida íntima de los esposos. Después de tan largo tiempo, la Corte Suprema determinó que el fallecimiento se había debido a un aneurisma. Olórtiga tuvo que padecer injusta prisión por algunos meses.

Otro caso terrible: nueve años duró el proceso penal por el crimen de Miriam Fefer. De esos nueve, siete estuvo en la cárcel Eva Bracamonte, hija de la difunta, incriminada sin que nunca se le pudiera probar culpabilidad, autoría mediata o inmediata. Mientras duró el proceso, el público se fue enterando por los medios de particularidades de los hijos de la occisa que, enfrentados con odio y pasión malsana, y motivados por intereses económicos hereditarios, sacaron a relucir mil y un aspectos de su vida íntima, que nunca se hubieran conocido y que no tenían por qué hacerse públicos. Muy al comienzo del juicio, Alejandro Ospina Trujillo confesó ser el autor del crimen, indicando que al ser sorprendido por la Sra. Fefer robando en casa de ésta no tuvo más alternativa que matarla.

Tan grande es la tentación de traficar con intimidades que ni el Washington Post ni Newsweek, medios renombrados mundialmente, importantes, tuvieron reparo para entrar en detalles sobre la ropa de Mónica Lewinsky en el caso del affaire con Clinton.

Muchos casos más hemos visto en los que sin justificación seria se han puesto en exhibición menudencias íntimas (el caso Llamoja, el caso Marco Gabriel Arenas Castillo, tantos más).

En el ensayo no aparecen dos situaciones relacionadas con el derecho a la intimidad que han cobrado singular relieve con posterioridad al tiempo en que fue escrito y que hoy merecen comentario por la trascendencia que tienen.

Una es la ilegal injerencia que se produjo en las elecciones del país más importante de la tierra, los Estados Unidos, a través de la red social más grande del planeta: Facebook. Esto sucedió mediante la contratación por el comité 
de campaña de Donald Trump de la firma inglesa Cambridge Analytica, especializada en marketing electoral. Cambridge por su parte subcontrató a Global Science Research, una empresa de propiedad de Alexsandr Kogan, nacido en Rusia y que estudió y trabajó en Inglaterra. Fue Global la encargada de extraer indebidamente información de más de 50 millones de usuarios con la que se podía construir perfiles psicológicos de todos ellos que contenían además de sus datos personales (edad, religión, estado civil, sexo) su tendencia política, gustos y preferencias de toda clase, relaciones de amistad y trabajo, etc. Elaborados con esa información unos perfiles psicológicos, segmentaron por grupos a los más de 50 millones de personas cuya participación en las elecciones iba a ser ciertamente decisiva. Luego, a través de usuarios ficticios, emprendieron una campaña de mensajes escritos para determinar la reacción quedeberían conseguir en los diversos conjuntos deelectores: entrelos indecisos o indiferentes, para animarlos a actuar a favor de Trump; en los partidarios de Trump, para reafirmarlos en sus convicciones; en los simpatizantes de Clinton para hacerles desistir, empleando para ello el lema, repetido hasta el cansancio, de "Defeat crooked Hillary" (derrota a la corrupta Hillary). Tan refinado fue el programa empleado que para evitar ser rastreados o hackeados utilizaron un "temporizador antidestrucción". Y tanto fue el alcance de este método de injerencia que el itinerario que siguió Trump en toda su campaña así como el discurso que empleó en cada lugar estuvo marcado, orientado, por los resultados y las recomendaciones que se iban obteniendo con el uso del mismo. Se estima que los resultados decisivos de los estados de Virginia, Colorado y Florida, que al comienzo de la campaña eran inciertos o adversos, resultaron al final favorables por la tarea de injerencia.

En este caso la violación del derecho a la intimidad se ha producido, a nuestro juicio, primero por la obtención de datos personales cuya entrega no estaba autorizada por los usuarios. En segundo lugar por haber atentado contra la adopción autónoma de decisiones, influyendo en ellas a través de una forma de manipulación psicológica artera, engañosa y desleal.

Otra situación digna de mención y comentario es la aparición en los últimos tiempos de los llamados drones (del inglés drone, que significa zángano, y que alude al zumbido que producen dichos insectos, semejante al de los drones). Los drones son pequeñas aeronaves pilotadas a distancia que pueden incursionar donde no llegan por su volumen los helicópteros ni los aviones y que pueden realizar servicios valiosos en diversos órdenes, pero que también pueden servir para el espionaje comercial, industrial y también doméstico, personal. Para impedir que se emplee en esto último la Ley 30740, dada el año anterior para normar el uso de drones, incluyó este modo de uso entre las operaciones prohibidas. 